Peer-Reviewed Article

ISSN: 2162-3104 Print/ ISSN: 2166-3750 Online

Volume 6, Issue 2 (2016), pp. 451-477

(C) Journal of International Students

http://jistudents.org/

\title{
The Lived Experiences of Canadian-Born and Foreign-Born Chinese Canadian Post-Secondary Students in Northern Ontario
}

\author{
Fei Wang \\ University of British Columbia, Canada
}

\begin{abstract}
This phenomenological study provided an in-depth description of the internal meaning of the lived experiences of Canadian-born and foreign-born Chinese students in Canada and uncovered the differences in their social experiences. The study used semi-structured interviews to allow the participants to express their views on their lives in Northern Ontario, Canada. Four themes emerged: (a) perceptions of ethnic identity; (b) cultural integration; (c) perceptions of academic performance and $(d)$ the effect of Canadian education on career options. The study revealed that Canadian-born Chinese students differed from their foreign-born counterparts in their viewpoints on ethnic identity; their perceptions concerning acculturation; and academic performance. They shared similarities in their views about Canadian and Chinese educational systems, teaching styles, and their career expectations.
\end{abstract}

Keywords: Ethnic identity, cultural integration, acculturation, and academic performance

Internationalization has changed the landscape of education in many countries and enhanced the mobility of people who are seeking quality education in countries other than that of their origin, particularly in 
English-speaking countries. This inevitably leads to immigration for education. Canada is one of the host countries where immigrants have made valuable contributions to the diversity and the prosperity of educational institutions. According to the Affiliation of Multicultural Societies and Services Agencies of British Columbia (2013), Canada welcomed 104,777 international students in 2012, a 51\% increase since 2003. Twelve percent of them are coming from one of the five source countries - China (Four other are India, 12\%; South Korea, 8\%; France, 5\%; and the United States, 5\%). Among all the provinces in Canada, Ontario has admitted the largest number of international students $(45,401)$ in the same year. The international students not only contribute to cultural and linguistic diversification and bring in substantial income to the local communities, but also become a valuable source of highly skilled labor to Canada's economy (Department of Foreign Affairs and International Trade, 2012).

As is the case with international students, the waves of immigration have also added to Canada's ethnic and cultural composition. According to Statistics Canada (2011), one out of five people in Canada's population is foreign-born. Over the past five years, $15.3 \%$ of foreign-born people who arrived are Chinese. A small proportion $(2.8 \%)$ of Chinese were third generation or more. The reciprocal agreement on February 28, 2015 between China and Canada on issuing long-term and multiple-entry visas for Chinese and Canadians further facilitates the entry of Chinese to study and live in Canada.

The push to attract more students to college and university campuses coincides with the increasing immigrant population. As the foreign-born and Canadian-born Chinese students add more diversity and vibrancy to educational institutions in Canada, the influx also poses challenges to colleges and universities on how to maintain the high quality and levels of services to their students. Knowing their lived experiences and needs and concerns becomes paramount to better serve these students, enrich their Canadian experience, and enhance their personal and professional growth. While there has been research on Canadian Chinese regarding language problems, identity, and second-generation education (Cheng \& Erben, 2012; Chow, 2001; Dyson, 2001; Kaufman, 2004; Leedham, 2015; Zhang \& Zhou, 2010), there is still a gap in research concerning Canadian Chinese 
from other national origins (those who are Chinese Canadians but were originally born outside of Canada). In view of the paucity of research on the differences and similarities between Canadian-born and foreign-born Chinese students, this study is intended to extend the literature by exploring and comparing the lived experiences of Canadian-born and foreign-born Chinese students at a university in Northern Ontario. The main research question guiding this study is: What are the differences and similarities between Canadian-born and foreign-born Chinese students in Northern Ontario in their lived experiences as post-secondary students.

This study prompts us to rethink educational practices on students of different ethnic and cultural origins and builds on the need to explore the constraints, uncertainties, and disorientations that may face these students. Given a growing Chinese student population in post-secondary education in Canada, understanding their experiences will inform future practice that supports their success academically and socially. Documenting the differences and similarities in their attitudes, beliefs, and perceptions will also help provide university student service offices, professors, and other stakeholders with useful information to effectively address the needs, interests, and aspirations of students in similar contexts, thereby helping them better adapt to school and community life in Canada.

\section{DEFINITION OF TERMS}

Chinese Canadians are people of Chinese descent or origin who were born in or immigrated to Canada. They are Canadians by naturalization, but ethnically, their ancestral roots can be traced back to China (Li, 1998). Canadian-born Chinese are people of Chinese descent or origin who were born in Canada. They are Canadian citizens by birth (Li, 1998). Chinese Canadians of later generations are referred to as "CBC" [Canadian-Born Chinese], a parallel to "ABC" [American-born Chinese]. Foreign-born Chinese are people of Chinese descent or origin who have immigrated to Canada with Chinese as their first language. They are either permanent residents or Canadian citizens by naturalization. 


\section{LITERATURE REVIEW}

Three strands of research contribute to the understanding of the lived experiences of Chinese Canadian students in Northern Ontario. The first strand presents theories of the relationship between ethnic identity, cultural capital, culture and social affiliation; the second discusses parents' expectations of their education and career aspiration; and the third strand reviews research on language proficiency, schooling and academic performance.

\section{Ethnic Identity, Language and Acculturation}

Identity is a matter of 'becoming' as well as 'being' and it is "subject to the continuous 'play' of history, culture and power" (Hall, 1990, p. 225). Identity is formed through socialization in the society where it undergoes a process of constant change, modification, and adjustment. Ethnicity refers to a specific characteristic of shared unique cultural tradition, and a heritage that persists across generations (Guanipa, 1998). In other words, ethnicity refers to membership in a group with a common cultural tradition or common national origin. In the light of growing ethnic diversity in Canada, Chinese immigrants are more likely to face cultural discontinuity in multicultural Canada (Li, 1998). The issue of changing cultural identity among Canadian-born Chinese has been widely discussed within that community for several decades (Kobayashi \& Preston, 2014; Lai, 2012; Shan \& Guo, 2013). Depending on life experiences and current situations, the salience of ethnicity varies among different generations of Chinese immigrants in Canada.

For Chinese Canadian students, the complications of identity formation may arise as a product of skin colour, language differences, behavioral patterns, cultural values and norms, social stereotypes, parents' misconceptions and fears (Guanipa-Ho \& Guanipa, 1998), and confusion on their sense of belonging (Kobayashi \& Preston, 2014). However, when it comes to foreign-born Chinese immigrants, Lay and Verkuyten (1999) discovered in their research on Chinese Canadian adolescents that ethnicity is more salient for foreign-born Chinese adolescents compared with their Canadian-born counterparts. This implies that there may exist some social or cultural factors 
concerning perceptions of their identity among Chinese Canadian students. Lay and Verkuyten (1999) conclude that these two groups might differ in terms of their life experiences and their views of their situations or contexts.

Language is not merely a vehicle or tool for expressing the thoughts, perceptions, sentiments, and values of a culture, but it also represents a fundamental mode of collective social identity, indicating who is included or excluded (Gudykunst \& Schmidt, 1987). Isajiw (1990) maintains that language teaches members of an ethnic group their cultural heritage, and the process of language learning is "the simplest practical way of imprinting ethnic identity" (p. 81). De Vries (1990) states that language retention is a necessary condition for maintaining ethnic identity and survival, and mother tongue loss may imply a loss of associated ethnicity. These two studies reveal an interrelationship between language and ethnic identity, which implies that one of the ways to maintain ethnic identity is to use one's own language. A recent meta-analysis also confirms a statistically significant moderate positive correlation between sense of ethnic identity and proficiency of heritage language across different ethnic groups (Mu, 2014). Of concern, then, is that most second-generation Chinese Canadians begin to lose competence in their first language as they develop fluency in a second, or third language, while their parents are still struggling to learn the second language (Buki, Ma, Strom \& Strom, 2003). Due to this communication barrier, parents are less able to "socialize their children in the values, beliefs, and practices that are important to the family and community" (Wong, 1991, p. 6). Their children, though, having a stronger preference for English after schooling, tend to be more enthusiastic and committed to heritage language learning "when they have found their own place in the English-speaking world and when they see themselves as linguistic and social equals to others" (Zhang, 2010, p. 58).

Ghosh (2000) contends that "identities are constantly shifting and renegotiable, and the search for new/modified identities, therefore, is a coping mechanism in the confusion caused by migration and global changes" (p. 279). Ghosh's argument reveals that identity is no longer static, but formed in social process. Children from varied cultural identities may integrate different cultures and assume a new form of cultural identity. Their efforts to construct 
personal identity may redefine the norms of group identity. Interestingly, children find it more challenging to identify as bilingual than as bicultural (Fielding \& Harbon, 2013). They do not develop two cultural identities but integrate both of their cultures into one unique identity.

To immigrant families, the pace of individual acculturation varies among parents and their children. Usually, children adjust more rapidly than parents (Abouguendia \& Noels, 2001; Ying, 1999). In other words, parents tend to be less acculturated to the mainstream culture than their children. Buki, Ma, Strom and Strom (2003) point out "intrafamily variance in acculturation introduces conflicts between the traditional values of parents and the new values embraced by their children" (p. 128). These conflicts may lead to intergenerational isolation within Canadian Chinese families, thus posing a threat to "the integrity of a traditionally collectivistic culture, in which the strength of the family rests on the strength of the individual members" (p. 128). There can be a positive aspect to these conflicts. Ghosh (2000) argues that identity no longer bears a static, unitary trait, and it is now regarded as being formed in a social process because human beings are always in the making. In Canadian Chinese families, bilingual adolescents who do not develop separate cultural identities might be able to shift from one cultural self-concept to another (Ross, Xun \& Wilson, 2002). In this sense, bilingual Canadian Chinese may benefit from valuing both of the cultures rather than choosing one over the other.

\section{Parents' Expectations and Career Aspiration}

Families from different cultures hold different parental expectations, underlined with different interpretations accordingly (Delaney, Harmon \& Redmond, 2011; Found \& Sam; 2013; Hussain \& Rafique, 2013). Traditionally, Chinese parents have great expectations of their children, and parents have been identified as the most important contributor to children's education and career development (Li, 2001). Parents from Canadian Chinese families ground their expectations for their children in Chinese tradition and their deeply rooted Chinese cultural heritage. "To understand the expectations of Chinese immigrant parents in Canada, it is essential to contextualize their experiences because their expectations are derived 
and conditioned by particular social, cultural, historical, and family circumstances" (Li, 2001, p. 478).

Confucianism in China has led to a firm belief that nothing is more important than formal education ( $\mathrm{Li}, 2001$; Li, 2003). This influence is fundamental to Chinese at home and abroad. In terms of parenting, Chinese parents stress that a certain amount of pressure will ultimately produce positive outcomes on their children's education ( $\mathrm{Li}, 2001)$.

Confronted with an entirely new world that can be a far cry from their original expectations, Canadian Chinese parents have to make painful adjustments to Canadian society. Li (2001) argues that "the parents' understanding of Canadian society and their perception that visible minorities are disadvantaged prompted them to form a minority ideology and also to advise their children to pursue sciencerelated careers" (p. 477). In a comparative study of American, Chinese-American and Chinese families, Chen (2001) finds that both Chinese parents and students have more positive attitudes toward science education than their American counterparts. Chinese parents place greater emphasis on self-improvement, set higher standards, and more often help their children to learn science than do American parents. To avoid competing with mainstream society, Canadian Chinese families encourage their children to excel in science subjects so as to take up professions in engineering and other technical fields (Li, 2001).

Moreover, Chinese immigrant families have to adjust to the differences in the Chinese and Canadian educational systems,

because values advocated in the Canadian educational system may not be consistent with Chinese cultural and educational values, immigrant Chinese parents in Canada may transmit to their children messages about expectations and educational success which differ from the messages their children receive in school. (Zhang, Ollila \& Harvey, 1998, p. 182)

Due to weaknesses in home-school communication, Canadian Chinese students feel that the generation gap is widening in the presence of the conflict between the home culture and school culture (Li, 2003). 
Selecting a career might be a daunting task for Chinese youths, particularly for those from Canadian Chinese families, because they have to balance their own interests with what is acceptable to their parents (Ma \& Yeh, 2005). So family plays an important role in the process of career development of Canadian Chinese youth. The strong parental influence is "associated with more traditionally acceptable career choices, such as engineering, medicine, and computer science" (Ma \& Yeh, 2005, p. 337).

\section{Language Proficiency, Schooling and Academic Performance}

Most Chinese have a firm belief that quality education is the key to future success. Among Canadian Chinese, such respect for education has been further strengthened rather than weakened $(\mathrm{Li}$, 2003). As new members of Canadian society, they not only risk losing their own ethnic identity in a multicultural context, but many also run short of economic, social and cultural resources (Buki, Ma, Strom \& Strom, 2003). As a result, "many immigrants look to education especially, their academic credentials - to compensate for their limitations and to enable them to procure the resources they need" (James, 2004, p. 43). Canadian education not only broadens their career choices, but also serves as a buffer to integrate into the society. James (2004) claims that "immigrants, themselves, have played an important role in helping to establish an educational system, in which the assimilationist approach and the claim that 'all students are the same' gives way to a vision of equitable education based on principles of justice, fairness and respect for difference" (p. 43). With their advocacy and efforts, Canadian Chinese immigrants are changing the educational realities of schooling and managing to create an educational system responsive to their needs, interests and expectations as well.

Although many Canadian Chinese are helping to create a new system, the majority of students and their families still have difficulty adjusting to the cultural context of school. Obviously, "in order to participate fully in the economic, political, educational, and social domains of Canadian society, minority students must strive to attain a high level of English proficiency" (Chow, 2004, p. 321). So language proficiency exerts a strong positive effect on school performance. Because many Canadian Chinese families put a great deal of pressure 
on their children to excel in school, these children have a high educational attainment. They are often motivated to succeed academically and provide positive role models for their peers in school (Campey, 2002).

Considering different family and educational backgrounds among Canadian-born Chinese and foreign-born Chinese students, there might be a difference in their behavior and perceptions toward schooling. Kaufman (2004) found in her research conducted in the United States that second-generation Chinese students appear to value more entertaining, knowledgeable teachers, but are not willing or able to work hard for school success, whereas Chinese immigrant students work very hard, and value demanding teachers, difficult curriculum and more discipline.

\section{RESEARCH METHOD}

This study used a phenomenological method. Phenomenology is concerned with the study of experience from the perspective of individuals and it "reawakens or shows us the lived quality and significance of the experience in a fuller or deeper manner" (van Manen, 1990, p. 10). It is a systematic method of uncovering and describing the internal meaning of lived experience through the analysis of participants' descriptions. It allows the participants to describe their thoughts, feelings, and memories - their stream of consciousness - along with a description of the situation in which the experience occurred. Given that this study aimed to look into the lived experiences of Chinese Canadian students, such methodology is appropriate in that it illuminates the specific and allows the researcher to gather deep information and perceptions through interviews and discussions.

The primary method for data collection was semi-structured interviews conducted in English. The interviews enabled participants to discuss their interpretations of the world in which they live and offer their personal views and perceptions of situations. Each interview lasted from thirty to forty-five minutes and was audiorecorded and transcribed for analysis. 


\section{Table 1: Participants’ Profile}

\begin{tabular}{|l|l|l|}
\hline & Andrew & $\begin{array}{l}\text { born in a Hong Kong immigrant family in Toronto; } \\
\text { speaks some Cantonese and is fluent in English. He } \\
\text { attended elementary and secondary school in } \\
\text { Toronto, before attending university in Northern } \\
\text { Ontario. His childhood aspirations were to become a } \\
\text { fireman, but his parents thought it was dangerous for } \\
\text { him and encouraged him to study engineering. }\end{array}$ \\
\cline { 2 - 4 } & Charles & $\begin{array}{l}\text { born in a Hong Kong immigrant family in Montreal; } \\
\text { speaks some Cantonese and French, and is fluent in } \\
\text { English. He attended French public schools in } \\
\text { Montreal, and later a private English school because } \\
\text { of bullying in the former school. He obtained his } \\
\text { degree in Montreal and came to the university for his }\end{array}$ \\
B.Ed.
\end{tabular}


In order to enhance research validity and reliability, the interview transcripts were sent back to participants for verification and confirmation.

A colleague was invited to check codes and themes generated in data analysis. All participants are from the same post-secondary institution located in a city with a population of 121,000 . There were approximately 300 international students with a very small number of Chinese students at the time the study was conducted. This Northern Ontario University was chosen as it was at a very early stage of internationalization and is undergoing unprecedented change to increase numbers of students from both within and beyond the national borders. Unlike larger cities such as Toronto, Montreal, and Vancouver, the low cost of living, affordable tuitions, and smaller communities also add to its attraction for students.

A purposeful sampling was employed when selecting the participants. This qualitative study does not intend to generalize but to suggest a case of a small group of students who are studied in a particular context. Given only a small number of Chinese Canadians studying in this university, three Canadian-born and three foreignborn Chinese students were selected. Three participants were male and three were female (Table 1). All participants in this study were students in their first or second year of bachelor's or master's programs. They major in nursing, engineering, and education.

Data were analyzed throughout the research project using constant-comparative approach (Bogdan \& Biklen, 1998). Commencing with the coding of interview data, regularities and patterns were identified in the transcribed responses of the participants, and keywords and phrases were extracted to represent these regularities and patterns (Bogdan \& Biklen, 1998), from which the preliminary codes were developed. After the preliminary codes were refined with member checking, they were combined and assigned to form categories, which were clustered around themes, corresponding to the literature review and the research questions. To ensure the confidentiality and anonymity of the participants, pseudonyms are used in the presentation of findings. 


\section{RESEARCH FINDINGS}

The research findings show that Canadian-born Chinese students differed from their foreign-born counterparts on their viewpoints on ethnic identity, their perceptions of acculturation, and academic performance. They also shared some similarities, including their views about the Canadian and Chinese educational systems, teaching styles, as well as their expectations for their respective future careers.

\section{Perceptions on Ethnic Identity}

Rosenthal and Feldman (1992) found that Chinese adolescents living in Australia and the United States had a tendency to define themselves as Chinese. One would assume that foreign-born Chinese students would be more likely to identify themselves as Chinese compared to their Canadian-born counterparts. It was surprising to note that two Canadian-born (Han \& Sun) and two foreign-born participants (Andrew \& Tina) felt more aligned with Chinese culture. Although they immersed themselves in the dominant English or French Canadian culture, they viewed themselves as separate from the wider Canadian context. Within the mainstream Canadian culture, the foreign-born participants still retained the behaviors, beliefs, and values of the Chinese culture, which they found not only constantly clashed in various ways with Western culture, but also enhanced their awareness of their ethnic identity. In a sense, they were more preoccupied with the idea of how to acculturate into the new society than how to construct their identities within the Canadian social framework. This process becomes more selective as Han put it: "I just be myself! I accept something which I like in Canada, but I don't force myself to accept those things that I don't like."

In contrast, two of the Canadian-born counterparts (Andre \& Tina) were more fluid in relating to two different cultures and ethnic identities. They viewed themselves as Chinese in terms of ethnicity, but felt embarrassed by or even guilty for their paucity of Chinese cultural heritage and knowledge. The Canadian-born Chinese students were creating culture in a new context, by using one portion of their parents' culture while simultaneously adopting the dominant culture. For example, Canadian-born Andrew commented: "I am Chinese because of the blood, culturally I understand very little... when I was 
young, we did celebrate Chinese New Year. We always ate Chinese food. So more Chinese, and as for Mandarin, usually a little!" This process of the reconstruction of identity is what Hall (1990) calls a process of "becoming and being." It is a social process where people search for new meanings of identity and redefine norms of identity at the individual level (Ghosh, 2000).

On the other hand, for Canadian-born students of Chinese origin, being exposed to more than one culture may lead to identity conflicts and confusion (Ghosh, 2000). They may seek reconciliation in the process of identity construction by integrating two different cultures and creating a mixture of cultures on an individual basis. This was the case of Charles in this study as he indicated: "I follow lots of things that Chinese people do. At the same time, I am also...I am Canadian. I think more Chinese, maybe." He held that culturally, he was little bit of both. By inheriting Chinese culture from his parents, he built up a connection to the collective identities to which his parents belong, while through Canadian culture, he opened a door to wider Canadian society as well. Thus, he unintentionally created a space for himself by assuming a dual identity. This dual identity in turn lent to a further interpretation on his struggle over identity construction. This clearly supports Ghosh's (2000) argument that "strong ethnic identification with one's own ethnic culture as well as with the dominant culture is the ideal way to integrate because one needs to know where one is coming from in order to know where one is going" (p. 279).

With regard to his ethnic identity, foreign-born Chinese student Jun stated that he did not really care whether he was Canadian or Chinese. This finding is consistent with Crocker, Luhtanen, Blaine and Broadnax's (1994) argument that the salience of ethnicity varies in accordance with life experiences and current situations. Jun's personal experience at school in Taiwan, his parents' expectations and his migration to Canada appear to have exerted a subtle influence on his viewpoints towards ethnic identity.

In their search for new or modified identities, both foreignborn and Canadian-born Chinese students seek a balance between their Chinese cultural heritage and mainstream Canadian culture. Foreign-born Chinese students were highly aware that their deeply rooted cultural values, beliefs, and behaviors were an indelible 
indicator of their identity, yet they were also concerned more with how to adjust to Canadian society than how to become Canadians, while their Canadian-born counterparts were struggling over identity in a larger Canadian society from the day they were born.

\section{Cultural Integration}

Cultural integration highlights Chinese Canadian students' perceptions of fitting into social and academic life in Canada.

Perceptions of fitting into the society. In terms of cultural integration into society, the Canadian-born Chinese students differ from their foreign-born counterparts in two aspects: culture-specific knowledge from parents, and difficulties experienced at the beginning of school. They shared the view on the importance of a network of Chinese friends.

All Canadian-born participants acquired their formal education in Canada. Their parents, who retain traditional Chinese knowledge were their source of information of traditional Chinese culture. The second generation differs from their parents in that they have minimal knowledge of Chinese culture and minimal Chinese language skills. Their cultural norms are different from those of their parents because of their adapting English or French-Canadian cultures. Andrew stressed the importance of Chinese literacy and regretted his neglect of cultural inheritance: "Because it will be very useful for my career, and also my life to know how to communicate with Chinese people, 'cause that's my culture. But I totally ignored that part of my life." Previous observations of immigrant families show that the pace of individual acculturation varies, with the second generation usually adjusting more rapidly than their parents (Garcia Coll, Meyer, \& Brillon, 1995; Ying, 1999; Buki, Ma, Strom and Strom, 2003).

Cultural integration requires a high level of involvement in the native ethnic group (Lanca, Alksnis, Roese and Gardner, 1994). Both Canadian-born and foreign-born students deemed the acquisition of Canadian education as an expedient accommodation to Canadian society. Supposedly, Canadian-born Chinese students should be in a better situation to easily adjust to the local culture since they have been exposed to it since childhood (Buki, Ma, Strom and Strom, 
2003). Nevertheless, the Canadian-born Chinese students found it difficult to acclimate themselves at the beginning of their formal schooling. Charles commented on his unhappy school days: "Yeah, bullying! It is not just related to being Chinese. I guess being Chinese was contributing to it. So coincidence may be the reason." Prior to school attendance, second-generation Chinese learned primary Chinese, a tool only employed to communicate with their parents at home, and to acquire traditional attitudes, values and behaviors inherited culturally from their Chinese parents. With increasing contact with other ethnic group members within their neighborhood or at school, they became aware of differences in various aspects of life. Their perplexity and curiosity about mainstream culture mingled with their longing to be part of it. They believed that receiving a local school education would minimize their difference and enhance their social status (James, 2004). For example, Andrew recalled how he resisted going to a Chinese school: "I grew up here. Again I wanted to fit in with the rest of children, right? And being in a Chinese school would separate me from that. That's why I didn't want to go." Canadian-born Chinese students were able to integrate into Canadian society quite easily, thanks to their early exposure to the dominant English language as well as mainstream culture. This lends support to Chow's (2001) argument, "Proficiency in English is undoubtedly a prime consideration in the rapidity and ease with which immigrants adapt to an English-language-dominated milieu" (p. 191).

Both Canadian-born and foreign-born Chinese students have a tendency to associate with other Chinese students, as Andrew stated: "My group of friends I hang out with in high school were Chinese, because just similarities helped with the connection, very easy... There is so much common stuff which friendship was built from there." This is consistent with Minichiello (2001), who found similar results.

Comparatively, foreign-born Chinese students experienced more difficulties in adapting to Canadian society. Their difficulties were related to cultural difference, language barriers, personality, financial situation, and different social environments.

Geertz (1973) defines culture as "a system of inherited conceptions expressed in symbolic forms by means of which men [sic] communicate, perpetuate, and develop their knowledge about 
and their attitudes toward life" (p. 89). Engrained with cultural attitudes, beliefs, and values, foreign-born students found it hard to modify and alter their way of thinking, feeling, valuing, and acting when confronted with a different set of social standards and norms. They did not necessarily share interests, opinions, or values with local people. As Han put it:

If there were a chance, I'd love to make friends with them. We cannot get to that close relationship because we have cultural differences. We are interested in different things. We had different opinions on different things. That's too hard to get too close [with them].

Difficulty communicating further discouraged their attempt to approach and befriend local people, and maximize the possibility of acculturation. Such finding supports Lay and Verkuyten's (1999) earlier research that foreign-born students tend to feel less accepted and more like minority group members compared with their Canadian-born counterparts.

Second language proficiency is related to acculturation (Lanca, Roese, Alksnis, \& Gardner, 1994), because language is the primary requirement for communication and acquisition of information about the new society. Two foreign-born participants (Han \& Sun) were troubled by their poor language skills. To communicate, they have to learn how to listen, and how to convey their meaning accurately (Campey, 2002), and this, unfortunately, was a significant challenge for the foreign-born Chinese students. Good mastery of language is a priority for foreign-born students to get acclimated to Canadian society as Mesch (2003) indicated that "the acquisition of the local language by immigrants is also important in terms of the social reaction to them" (p. 42).

In relation to second language acquisition, Han and Sun pointed out that personality also plays a role in language learning and social adaptation. Sun stated: "Personality is important. If you're a talkative person, maybe you can overcome this difficulty much better and faster." Specifically, an active or affirmative personality may contribute more positively to second language acquisition than a passive and taciturn one. Attributes of shyness among Chinese 
students may hinder their language attainment and social adjustment. So far, many studies have been conducted on second language acquisition and acculturation (Young \& Gardner, 1990; Lanca, Roese, Alksnis, \& Gardner, 1994; Noels, Pon \& Clement, 1996), however there is dearth of research discussing the effect of personality on second language acquisition. Future research is recommended to address this area as it may further illuminate the lived experiences of Chinese college students in Canadian post-secondary institutions.

One interesting point revealed by foreign-born participants is that their financial situation hampered their social integration. Without any steady income, foreign-born students generally led a frugal life. Their tight budget restricted their access to the local media and involvement in social life, which in turn minimized their likelihood of social adaptation. For instance, Han observed:

One more thing is when we came here, we are just poor students. So we don't have money to pay for the TV cable. We are kind of isolated from the media. That's why when people are talking about something, we don't know what it is, because we are isolated from the media.

This echoes Cole's (1998) argument that the acculturation process is impacted by factors, such as post-migration stressors which are related to poverty or socioeconomic status. In what way does socioeconomic status of immigrant students affect acculturation? Further research is suggested to probe into this area.

Different social environments may have different effects on acculturation. Two foreign-born participants (Sun \& Jun) worked before they pursued their degrees at school, and provided insightful perceptions of the different social contexts. Language proficiency was important in both contexts (Chiswick \& Miller, 1998), but participant Sun acknowledged that it was much easier to associate with classmates at school than with work colleagues. Her statement indicates that interpersonal relationships in the workplace versus school may differ and that Canadian education may help to facilitate cultural adaptation. Many immigrants look to Canadian education to compensate for their limitations (James, 2004). Jun, who immigrated to Canada earlier than the other two stated that he could "fit in the 
society pretty well", which supports the argument that the longer the exposure to the local language, the stronger the language proficiency (Mesch, 2003).

Perceptions on fitting into the academic life of the university. All foreign-born participants found it difficult to adjust to academic life. To foreign-born Chinese students, language still posed an obstacle, both in and out of the classroom, which made their studies more demanding and time-consuming in comparison with their Canadian-born counterparts. Language is always a concern to Han, particularly for class participation and presentation:

Oh, that's hard. I always want to escape from that, because you have to speak out in front of a lot of people. Sometimes, your mind just stops working. It goes blank and empty. Yes, you can't think about anything, because I am nervous. I think language is a big thing.

The foreign-born students tended to spend more time in their academic work and less time in extracurricular activities. This is not because they are not motivated for extracurricular activities but because their academic work takes up a considerable amount of their time, which does not allow for other activities. Kaufman (2004) reported that immigrant Chinese students are motivated to work harder than their second-generation Chinese peers.

As for the university social life, the Canadian-born Chinese students were more socially active and had a stronger sense of community than the foreign-born students. However, at the university, both groups had one thing in common, the tendency to associate with Chinese friends. This result again supports Kaufman's (2004) and Lay and Verkuyten's (1999) findings that both immigrant and nonimmigrant Chinese students manage to develop an intimate community among Chinese students, but non-immigrant students may be more active mixing with a diverse population of students.

\section{Perceptions on Academic Performance}

The challenges facing both Canadian-born and foreign-born Chinese students in their academic performance are manifested in 
terms of language proficiency, teaching style, motivation, and educational systems.

Language issues seem ubiquitous in the lives of the foreignborn participants. Except for Jun, who had a good mastery of the English language, the other two foreign-born Chinese students (Han $\&$ Sun) indicated that their academic performance largely depended on their language proficiency. Such proficiency is associated with higher academic achievement among minority immigrant students (Chow, 2000; Rumberger \& Larson, 1998; Vernez \& Abrahamse, 1996).

Familiar with a traditional teacher-centered educational background in China, all foreign-born Chinese students enjoyed the new teaching styles at the Canadian university. In China, hardworking, demanding teachers, and difficult curriculum are highly valued at schools (Kaufman, 2004). "The educational systems emphasize rote memorization rather than skill development and problem solving; self-expression may be actively discouraged" (Campey, 2002, p. 44). In Canada, professors are more supportive and helpful. The participants' particular preference for a student-centered educational model illustrates benefits of this pedagogical approach.

There is a discrepancy between the foreign-born and Canadian-born Chinese students in their academic behavior. Canadian-born Chinese students indicated that motivation played an important role in their studies and they appreciated the more entertaining teachers who are able to use diverse instructional strategies and technology to engage their students. To some extent, they were unwilling or unable to work diligently to succeed at high academic levels, while their foreign-born counterparts believed in working hard to accomplish success. This is consistent with findings reported by Ogbu and Simons (1998), who in their cultural-ecological theory of minority school performance, note that voluntary minorities' attitudes toward schools are influenced by the "back home" comparison, and many tend to believe hard work will lead to success.

Being exposed to two entirely different educational systems, foreign-born participants appeared to embrace the Canadian educational system, where creativity and independent thinking are highly encouraged. The Canadian-born Chinese students enjoyed the Canadian educational system as well. However, they differ from their 
foreign-born counterparts in that they liked the system not because of the creativity or the independent thinking teachers encourage, but because of the perceived ease of school programs and relaxed school atmosphere. They thought they were lucky not to be in Chinese schools where their teachers would push them to an unreasonable degree. The second-generation students talk of wanting more entertaining, knowledgeable professors while not willing or able to work as hard for school success (Kaufman, 2004).

\section{The Effect of Canadian Education on Career Expectation}

The foreign-born students had much clearer educational and career expectations, and their choice of school speciality as well as career expectation was affected more by their parents' opinions or consideration of the employment market than personal preferences. This is also evident among the Canadian-born Chinese students, but relatively, their personal preference plays a stronger role in their career choice.

Moreover, the foreign-born Chinese students placed great emphasis on the importance of a Canadian university education because they regarded it as a key to open doors in their new life in Canada, even if they were not sure what their future career options would entail. Their Canadian post-secondary education serves as a "buffer" for them to gain time and opportunities to get acclimated to Canadian culture and facilitate their integration to the Canadian society. It also constitutes part of their "local experience" which they expected would add more credibility to their overall skills and knowledge and enhance their competition in the job market in Canada. James (2004) argued that "as new members of the society, they frequently lack economic, social and cultural resources, many immigrants look to education - specifically, their academic credentials - to compensate for their limitations and to enable them to procure the resources they need" (p. 43).

\section{DISCUSSION AND CONCLUSION}

The study highlights the importance of language acquisition and use among foreign-born Chinese students for both cultural integration and school performance. How and why immigrants acquire language 
proficiency and use the local language is "an important issue in countries that receive large waves of migration" (Mesch, 1991, p. 42). Undoubtedly, foreign-born Chinese students must attain a high level of English or French proficiency to allow them to fully participate in the social and educational domains of Canadian society. They also face the added challenge of language problems and of cultural integration, often struggling with a dynamic and complex array of traditional, cultural, and educational values. Here then, in Canada, they enter a new dimension of opportunity, the Canadian educational system.

The narratives of foreign-born students further reflect their deeply rooted cultural values, their aspirations for a promising life, their striving for excellence and their struggle to become visible in this new multicultural society. The problem remains, however, that despite their strenuous efforts to adjust to the contemporary Canadian culture, their second language attainment and Chinese cultural tradition still creates borders around mainstream culture in Canada. To break through the borders calls for proper language training and instructions as well as appropriate cultural orientation into local communities for foreign-born Chinese students (Kaufman, 2004).

This study provided insights into the determinants of acculturation among Canadian-born students of Chinese origin within a multicultural setting. Canadian-born Chinese students do not seem to be bound to the Canadian culture, and they do not characterize themselves in terms of the culture of their language choice. This finding contradicts the hypothesis of Lanca, Roese, Alksnis, and Gardner (1994) that "language choice can be seen as a major index of ethnic identity" (p. 328). The Canadian-born Chinese students, who have been exposed to both Chinese and Canadian cultures since the day they were born, tend to define themselves as Chinese in terms of ethnic identity, but culturally they modified their ethnic identity in various ways in response to social norms. They are more confident in their English or French abilities than their Chinese.

This study contributed to the understanding of school performance of Canadian-born Chinese students as well. The results shed light on how Canadian-born Chinese students develop their beliefs and attitudes about school education. In contrast with their foreign-born counterparts, who were more disciplined in their studies, 
Canadian-born Chinese students did not favor restrictive classroom environments. Canadian-born participants were motivated more by personal interests and preferences, and felt they were challenged rather weakly intellectually.

By and large, this study revealed the concerns and issues that hindered some participants' attempts at second language acquisition and cultural integration to Canadian society, and also illustrated anticipations and aspirations which motivated the participants' further efforts towards their future life and career in Canada. Although both groups were of Chinese origin, the difference in perceptions of their lives varied between Canadian-born and foreign-born Chinese students. Awareness of the difference is particularly important given the social context of Canada, where rights and needs of each minority group are equally cherished under the Multicultural Act (Bill C-93Canada, 1998). Whether they are foreign-born or Canadian-born, understanding their experiences becomes crucial to better meet their needs, enhance their learning opportunities, and cultivate them to be contributing members of the Canadian society.

\section{REFERENCES}

AMSSA (2013). Information Sheet. Retrieved from http://www.amssa.org/files/AMSSA\%20Info\%20Sheet\%20Issue $\% 2012 \% 20-\% 20$ International\%20Students $\% 20$ $\% 20$ Statistics\%20and\%20Trends.pdf

Abouguendia, M., \& Noels, K. A. (2001). General and acculturationrelated daily hassles and psychological adjustment in first- and second-generation South Asian immigrants to Canada. International Journal of Psychology, 36(3), 163-173.

Bogdan, R. C., \& Biklen, S. K. (1998). Qualitative research in education: An introduction to theory and methods. ( $3^{\text {rd }}$ ed.). Boston: Allyn \& Bacon.

Buki, L. P., Ma, T., Strom, R. D., \& Strom, S. K. (2003). Chinese immigrant mothers of adolescents: Self-perceptions of acculturation effects on parenting. Cultural Diversity \& Ethnic Minority Psychology, 9(2), 127-140.

Campey, J. (2002). Immigrant children in our classrooms: Beyond ESL. Education Canada, 42(3), 44-47. 
Chen, H. (2001). Parents' attitudes and expectations regarding science education: Comparisons among American, Chinese American, and Chinese families. Adolescence, 36(142), 305-313.

Cheng, R., \& Erben, A. (2012). Language anxiety: Experiences of Chinese graduate students at U.S. higher institutions. Journal of Studies in International Education, 16(5), pp. 477-497.

Chiswick, B. R., \& Miller, P. W. (1998). Language skill definition: A study of legalized aliens. International Migration Review, 32(4), 369-385.

Chow, H. P. H. (2004). The effects of ethnic capital and family background on school performance: A case study of Chinese Canadian adolescents in Calgary. Alberta Journal of Educational Research, 50(3), 321-326.

Chow, H. P. H. (2001). English-language use among Chinese adolescent immigrants. Alberta Journal of Educational Research, 47(2), 191-195.

Chow, H. P. H. (2000). The determinants of academic performance: Hong Kong immigrant students in Canadian school. Canadian Ethnic Studies, 32(2), 115-120.

Cole, E. (1998). Immigrant and refugee children: Challenges and opportunities for education and mental health services. Canadian Journal of School Psychology, 14(1), 36-51.

Crocker, J., Luhtanen, R., Blaine, B., \& Broadnax, S. (1994). Collective self-esteem and psychological well-being among White, Black, and Asian college students. Personality and Social Psychology Bulletin, 20, 503-513.

Delaney, L. Harmon, C., \& Redmond, C. (2011). Parental education, grade attainment and earnings expectations among univeristy students. Economics of Education Review, 30(6), 1136-1152.

Department of Foreign Affairs and International Trade, (2012). Economic impact of international education in Canada: final report. Roslyn Kunin \& Associates, Inc. Retrieved from http://www.international.gc.ca/education/assets/pdfs/economic_im pact_en.pdf

De Vries, J. (1990). Language and ethnicity: Canadian Aspects. In P. S. Li (Ed.), Race and ethnic relations in Canada (pp. 231-250). Toronto: Oxford University Press. 
Dyson, L. L. (2001). Home-school communication and expectations of recent Chinese immigrants. Canadian Journal of Education, 26(3), 455-476.

Fielding, R., \& Harbon, L. (2013). Examining bilingual and bicultural identity in young students. Foreign Language Annals, 46(4), pp. 527-544.

Found, A., \& Sam, D. (2013). Gender, sibling position and parental expectations: A study of Chinese college students. Journal of Family Studies, 19(3), 285-296.

Garcia Coll, C. T., Meyer, E. C., \& Brillon, L. (1995). Ethnic and minority parenting In M. H. Bornstein (Ed.), Handbook of parenting: Applied and practical parenting (pp. 189-209). Mahwah, NJ: Erlbaum.

Geertz, C. (1973). The interpretation of cultures. New York, NY: Basic Book.

Ghosh, R. (2000). Identity and social integration: Girls from a minority ethno-cultural group in Canada. McGill Journal of Education, 35(3), 279-296.

Guanipa-Ho, C., \& Guanipa, J. A. (1998). Ethnic identity and adolescence. Retrieved from

http://edweb.sdsu.edu/people/CGuanipa/ethnic.htm

Guba, E. G., \& Lincoln, Y. S. (1981). Effective evaluation. San Francisco, CA: Jossey-Bass.

Gudykunst, W. B., \& Schmidt, K. L. (1987). Language and ethnic identity: An overview and prologue. Journal of Language and Social Psychology, 6(3-4), 157-170.

Hall, S. (1990). Culture, identity and diaspora. In J. Rutherford (Ed.), Identity, community, culture and difference, (pp. 233-237). London: Lawrence Wishart.

Hussain, S., \& Rafique, R. (2013). Parental expectation, career salience and career decision making. Journal of Behavioural Sciences, 23(2), 62-76.

Isajiw, W. W. (1990). Ethnic identity retention, In R. Breton, et al., Ethnic identity and equality: Varieties of experience in a Canadian city (pp. 34-91). Toronto: University of Toronto Press.

James, C. E. (2004). Assimilation to accommodation: Immigrants and the changing patterns of schooling. Education Canada, 44(4), 4345 . 
Kaufman, J. H. (2004). The interplay between social and cultural determinants of school effort and success: An investigation of Chinese-immigrant and second-generation Chinese students' perceptions toward school. Social Science Quarterly, 85(5), 12751298.

Kobayashi, A., \& Preston, V. (2014). Being CBC: The ambivalent identities and belonging of Canadian-born children of immigrants. Annals of the Association of American Geographers, 104(2), 234242.

Lai, D. (2012). Ethnic identity of older Chinese in Canada. Journal of Cross-Cultural Gerontology, 27(2), pp. 103-117.

Lanca, M., Alksnis, C., Roese, N. J., \& Gardner, R. C. (1994). Effects of language choice on acculturation: A study of Portuguese immmigrants in a multicultural setting. Journal of Language and Social Psychology, 13(3), 315-330.

Lay, C., \& Verkuyten, M. (1999). Ethnic identity and its relation to personal self-esteem: A comparison of Canadian-born and foreign-born Chinese adolescents. Journal of Social Psychology, 139(3), 288-299.

Leedham, M. (2015). Chinese students' writing in English: implications from a corpus-driven study. Routledge Research in Education.

Li, G. F. (2003). Literacy, culture, and politics of schooling: Counternarratives of a Chinese Canadian family. Anthropology \& Education Quarterly, 34(2), 200-204.

Li, J. (2003). Affordances and constraints of immigrant Chinese parental expectations on children's school performance. Alberta Journal of Educational Research, 49(2), 198-200.

Li, J. (2001). Expectations of Chinese immigrant parents for their children's education. Canadian Journal of Education, 26(3), 477494.

Li, P. S. (1998). Chinese in Canada. Don Mills : Oxford University Press.

Ma, P. W., \& Yeh, C. J. (2005). Factors influencing the career decision status of Chinese American youths. Career Development Quarterly, 53(4), 337-347.

Mesch, G. S. (2003). Language proficiency among new immigrants: The role of human capital and societal conditions---the case of 
immigrants from the FSU in Israel. Sociological Perspectives, 46(1), 41-58.

Minichiello, D. (2001). 'Chinese voices in a Canadian secondary school landscape', Canadian Journal of Education, 26(1), 77-96.

$\mathrm{Mu}$, M. G. (2014). A meta-analysis of the correlation between heritage language and ethnic identity. Journal of Multilingual and Multicultural Development, 11, 1-16.

Noels, K. A., Pon, G., \& Clement, R. (1996). Language, identity, and adjustment: The role of linguistic self-confidence in the acculturation process. Journal of Language and Social Psychology, 15(3), 246- 264.

Ogbu, J. U., \& Simons, H. D. (1998). Voluntary and involuntary minorities : A cultural-ecological theory of school performance with some implications for education. Anthronology \& Education Quarterly, 29(2), 155-188.

Rosenthal, D. A., \& Feldman, S. S. (1992). The nature and stability of ethnic identity in Chinese youth: Effects of length of residence in two cultural contexts. Journal of Cross-Cultural Psychology, 23, 214-227.

Ross, M., Xun, W. Q. E., \& Wilson, A. E. (2002). Language and the bicultural self. Personality and Social Psychology Bulletin, 28(11), 1040-1050.

Rumberger, R. W., \& Larson, K. (1998). Toward explaining differences in educational achievement among Mexican American language-minority students. Sociology of Education, 70, 69-93.

Shan, H., \& Guo, S. (2013). Learning as sociocultural practice: Chinese immigrant professionals negotiating differences and identities in the Canadian labour market. Journal of Comparative Education, 49(1), 28-41.

Statistics Canada (2011). National Household Survey (NHS):Immigration and Ethnocultural Diversity

in Canada. Retrieved from http://www12.statcan.gc.ca/nhsenm/2011/as-sa/99-010-x/99-010-x2011001-eng.pdf

van Manen, M. (1990). Researching lived experience. London, Ontario: Althouse Press.

Vernez, G., \& Abrahamse, A. (1996). How immigrants fare in U. S. education. Santa Monica, CA: RAND Corp. 
Wong, F. L. (1991). When learning a second language means losing the first. Early Childhood Research Quarterly, 6, 323-346.

Ying, Y. W. (1999). Strengthening intergenerational/intercultural ties in migrant families: A new intervention for parents. Journal of Community Psychology, 27, 89-96.

Young, M. Y., \& Gardner, R. C. (1990). Modes of acculturation and second language proficiency. Canadian Journal of Behavioural Science, 22, 59-71.

Zhang, C., Ollila, L. O., \& Harvey, C. B. (1998). Chinese parents' perceptions of their children's literacy and schooling in Canada. Canadian Journal of Education, 23(2), 182-190.

Zhang, D. (2010). Language maintenance and language shift among Chinese immigrant parents and their second-generation children in the U.S. Bilingual Research Journal, 33(1), 42-61.

Zhang, Z., \& Zhou, G. (2010). Understanding Chinese international students at a Canadian university: Perspectives, expectations, and experiences. Journal of Canadian and International Education, 39(3), 43-58.

FEI WANG, $\mathrm{PhD}$, is an assistant professor in educational administration and leadership at the Faculty of Education, University of British Columbia, Canada. His research interests include educational administration and leadership, policy studies, equity and social justice, school diversity, international and comparative education. Email: fei.wang@ubc.ca 